\title{
Implementasi Costumer Relationship Management (CRM) Pada Sistem Informasi Penjualan Ban Di Toko Lingga Ban Berbasis Web
}

\author{
Ipan Supandi ${ }^{1}$, Fahmi Yusuf ${ }^{2}$, Fauziah ${ }^{3}$ \\ Fakultas Ilmu Komputer Universitas Kuningan \\ Jl. Cut Nyak Dien No.36 A, Kel. Cijoho Kuningan 45513

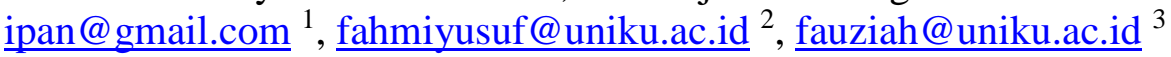

\begin{abstract}
Abstrak - Toko Lingga Ban adalah unit merek dagang yang terlibat dalam penjualan ban. Toko Lingga Ban hanya mengandalkan penjualan konvensional yaitu pelanggan harus datang ke toko dan melakukan transaksi di toko. Ini membuat pelanggan menjadi kurang tahu produk di pasar dan promosi yang ada. Toko Lingga Ban ingin memberikan layanan yang memuaskan dengan keinginan untuk menghadirkan inovasi dan kenyamanan bagi pelanggan. Untuk menyimpan Ban Lingga perlu sarana untuk mendukung transaksi penjualan dan promosi media yang efektif berarti menerapkan metode Customer Relationship Management (CRM) berbasis web. CRM adalah salah satu sarana untuk membangun hubungan baik dengan pelanggan dan untuk mendapatkan pelanggan baru. Sistem informasi penjualan berbasis web dibangun dengan metode pengembangan perangkat lunak waterfall, bahasa teknik pemrograman PHP, database MySQL sebagai penyimpanan data dan metode pengujian menggunakan black box \& white box testing sistem ini dapat digunakan oleh administrator, pelanggan dan arah. Administrator adalah orang yang mengelola seluruh sistem. Pelanggan dapat melakukan pemesanan Anda, konfirmasi pembayaran dan memiliki poin belanja. Arah melihat laporan instruksi, sistem ini diharapkan dapat menjadi solusi untuk mengatasi masalah dan untuk dapat meningkatkan penjualan Ban di Toko Lingga.
\end{abstract}

Kata Kunci: Sistem Informasi, Penjualan, CRM, Web, Toko Ban Lingga

Abstract - The store Lingga Tires is a trademark unit engaged in the sale of the tires. The store Lingga Tires only rely on the conventional sales namely the subscriber must come into the store and doing transaction at the store. This makes the customer became less know the products in the market and the existing promotion. The store Lingga Tires want to provide a satisfactory services with want to deliver innovation and convenience for customers. To store the Lingga Tires need a means to support the sales transaction and media promotions effective means of implementing the method Customer Relationship Management (CRM) web-based. CRM is one of the means to build a good relationship with customers and to acquire new customers. Web-based Sales information system is built by the method of software development waterfall, the language of PHP programming technique, MySQL database as data storage and testing method using the black box \& white box testing this system can be used by the administrator, customers and direction. The administrator is the person who manages the whole system. Customers can make your reservation, payment confirmation and have points shopping. The direction of instructions view report, this system is expected to be a solution to overcome the problems and to be able to increase sales in the Store Lingga Tires.

Key Words: Information System,Sale,CRM, Web, Store Lingga Tires

\section{PENDAHULUAN}

Persaingan dalam dunia bisnis pada saat ini sudah semakin maju, sehingga perusahaan perlu melakukan perubahan-perubahan strategi agar dapat meningkatkan bisnisnya. Di samping itu keberhasilan perusahaan bukan hanya terletak pada kualitas produk atau jasa, tetapi juga seberapa jauh upaya perusahaan memberikan pelayanan yang baik dan menyenangkan untuk memastikan mereka menjadi pelanggan yang setia. Hal ini membuktikan bahwa kecepatan, kemudahan, dan pelayanan kepada pelanggan menjadi 
pertimbangan utama para pengusaha untuk lebih mengembangkan sistem yang dimiliki agar dapat dijangkau oleh semua pelanggan.

Perkembangan dunia industri serta peran teknologi informasi dalam suatu organisasi bisnis telah membuat penggunaan strategis menjadi sebuah elemen kunci dalam menentukan keberhasilan sebuah perusahaan. Sementara itu dalam bidang manajemen, kekuatan-kekuatan strategis mempengaruhi persaingan global yang dihadapi oleh perusahaan domestik. Salah satu sektor bisnis tersebut adalah sektor otomotif, dimana Indonesia merupakan salah satu perkembangan otomotif terbesar di ASEAN setelah Thailand.

Toko Lingga Ban merupakan sebuah unit dagang yang bergerak di bidang penjualan suku cadang ban sepeda motor. Toko ini masih belum dapat mengoptimalkan aspek pemasarannya karena strategi yang diterapkan masih bersifat manual. Oleh sebab itu Toko Lingga Ban tidak mampu bersaing dengan toko lain yang memiliki potensi lokasi bisnis yang lebih strategis sehingga tingkat penjualan jauh dari harapan.

Pelanggan Toko Lingga Ban sering kali sulit untuk mengakses berbagai informasi tentang keterangan produk, informasi harga, ketersediaan stok barang dan promo yang diselenggarakan oleh pihak toko. Lebih jauh lagi pemasaran tidak dapat mencakup wilayah yang lebih luas karena keterbatasan media penyampaian promosi yang masih manual tersebut. Oleh karena itu, seiring berkembangnya teknologi informasi, maka perlu diterapkan suatu strategi yang lebih baik dengan mengimplementasikan suatu produk teknologi komunikasi informasi yang dapat membantu usaha ini menjadi lebih efektif dalam meningkatkan layanan marketing dan customer support, serta dapat menunjang pengambilan keputusan yang lebih baik bagi pemilik usaha.

Salah satu solusi dalam peningkatan layanan yang bisa dilakukan oleh pihak manajemen adalah dengan penerapan konsep manajemen hubungan dengan pelanggan atau Customer Relationship Management (CRM). Yaitu, sebuah filosofi bisnis yang menggambarkan suatu strategi penempatan client sebagai pusat proses aktivitas. Konsep ini telah dikenal dan banyak diterapkan untuk meningkatkan pelayanan di perusahaan.

Saat ini Customer

Relationship Management (CRM) sangat penting untuk membina hubungan antara pelanggan dan pihak yang bersangkutan serta memberikan informasi yang diperlukan oleh pelanggan mengenai data-data yang sedang dalam proses pengerjaan. Penerapan suatu teknologi informasi berguna untuk mewujudkan Customer Relationship Management (CRM) agar dapat berjalan dengan baik.

Berdasarkan uraian di atas penulis tertarik untuk mengangkat judul "Implementasi Costumer Relationship Management (CRM) Pada Sistem Informasi Penjualan Ban Di Toko Lingga Ban Berbasis Web."

\subsection{Rumusan Masalah}

Dari uraian latar belakang masalah sebelumnya, maka dapat diambil suatu perumusan masalah, yaitu:

1. Bagaimana membangun sistem informasi penjualan Ban berbasis Web?

2. Bagaimana mengimplementasikan metode Customer Relationship Management (CRM) Operasional 
pada sistem informasi penjualan Ban di Toko Lingga Ban?

\subsection{Batasan Masalah}

$$
\text { Agar tidak terjadi }
$$

penyimpangan masalah yang akan dibahas, maka permasalahan dalam penelitian ini dibatasi sebagai berikut

1. Sistem informasi yang akan dirancang adalah sistem informasi penjualan yang terdiri dari komponen Front Office sebagai pelayanan penjualan dan komponen Back Office sebagai pengontrol sistem dan manajemen.

2. Komponen Front Office meliputi modul katalog produk (Brand, Profile produk dan harga jual), modul pendaftaran membership, modul pembelian dan verifikasi pembayaran.

3. Komponen Back Office terdiri dari pengelolaan data produk, modul validasi pembayaran, modul pesanan produk, modul promo, dan modul biaya kirim.

4. Pembayaran dilakukan dengan melampirkan bukti transfer melalui ATM dan validasi pembayaran dilakukan setelah bukti transfer di aploud dan diketahui nomor rekening pembeli telah membayar sejumlah uang sesuai tagihan.

5. Pengiriman atau tarif ongkos kirim di sesuikan dengan agen pengiriman Jalur Nugraha Ekakulir (JNE) sesuai wilayah Kecamatan dan berat barang.

6. Metode pemecahan masalah dalam perancangan sistem ini menggunakan metode Customer Relationship Management (CRM) Operasional dan metode Waterfall sebagai pengembangan perangkat lunaknya.

7. Sistem informasi penjualan yang dirancang berbasi Web dengan menggunakan PHP sebagai bahasa pemrogramannya dan $M y S Q L$ sebagai pemrograman database.

\subsection{Tujuan Penelitian}

Dengan adanya rumusan masalah maka penulis membuat tujuan penelitian ini, dengan tujuan penelitian yaitu :

1. Membangun sistem informasi penjualan Ban berbasis web untuk memberikan kemudahan dan efisiensi dalam memasarkan produk tersebut.

2. Untuk menerapkan Customer Relationship Management (CRM) pada sistem informasi penjualan ban di Toko Lingga Ban.

\subsection{Manfaat Penelitian}

Adapun manfaat yang didapat dari penelitian ini :

1. Diharapkan bagi pihak penjual dapat menerapkan strategi pemasaran yang lebih efektif dan efisien dan meningkatkan pelayanannya terhadap konsumen.

2. Bagi konsumen diharapkan dapat memperoleh informasi produk yang dibutuhkan dengan cepat dan akurat serta proses transaksi pembelian yang lebih mudah dan praktis.

\section{METODE PENELITIAN \\ 2.1 Costumer Relationship management}

Menurut Buttle Francis (2004:48), CRM adalah strategi inti dalam bisnis yang mengintegrasikan proses-proses dan fungsi-fungsi internal dengan semua jaringan eksternal untuk menciptakan serta mewujudkan nilai bagi para konsumen sasaran secara menguntungkan

\subsection{Fase CRM}

Menurut Kalakota dan robinshon (2001:174), menyatakan bahwa CRM memiliki 3 fase, yaitu :

1. Menjaring pelanggan baru (Acquire). 
2. Meningkatkan kemampuan untuk menghasilkan keuntungan dari pelanggan yang telah ada (Enhance).

3. Mempertahankan pelanggan yang menguntungkan untuk kelangsungan hidup (Retain).

\subsection{Konsep CRM}

Menurut Buttle (2007:48) , konsep CRM bisa dipahami dalam tiga level, yaitu :

1. Strategic CRM berfokus pada pengembangan budaya bisnis yang bersifat customer centric.

2. Operasional CRM berfokus pada otomatisasi proses bisnis dalam kaitannya dengan upaya melayani pelanggan.

3. Analytical CRM berfokus pada pendayagunaan data pelanggan (meliputi data penjualan, catatan pembayaran, respons terhadap kampanye pemasaran, data loyalitas, daya layanan pelanggan dan sebagainya) untuk meningkatkan customer value dan company value.

\section{HASIL DAN PEMBAHASAN}

\subsection{Analisis Sistem Berjalan}

Selama ini Toko Lingga Ban menggunakan teknologi komputer sebatas hanya untuk keperluan administrasi dan belum dapat memanfaatkan sumberdaya yang ada secara optimal untuk keperluan pemasaran. Pemasaran yang dilakukan pada saat ini masih terbatas dan bersifat statis (tidak melakukan pemasaran secara aktif). Pelanggan yang membeli produk dari Toko Lingga Ban hanya pelanggan setia toko tersebut dan pelanggan yang sengaja mencari ke setiap toko.

Pelanggan yang berkunjung dilayani oleh bagian penjualan dan terkadang dilayani langsung oleh pimpinan. Kemudian pelanggan memilih produk yang akan di beli melalui katalog ban yang di tempel di etalase toko selebihnya mengenai produk, pelanggan akan menanyakan pada saat dilayani dan bagian penjualan selalu melihat ketersediaan stok dengan melihat pada buku catatan. Apabila terjadi kesepakatan penjualan kemudian bagian penjualan akan membuatkan nota transaksi dan mencatatnya. Di lain sisi bagian penjualan akan mengambilkan produk yang sesuai tersebut dan menyerahkannya pada teknisi untuk dilakukan pemasangan bila pelanggan meminta.

Analisis sistem yang sedang berjalan dari proses bisnis yang terjadi pada penjualan Ban di Toko Lingga Ban digambarkan melalui flowmap pada gambar 3.2 berikut ini.

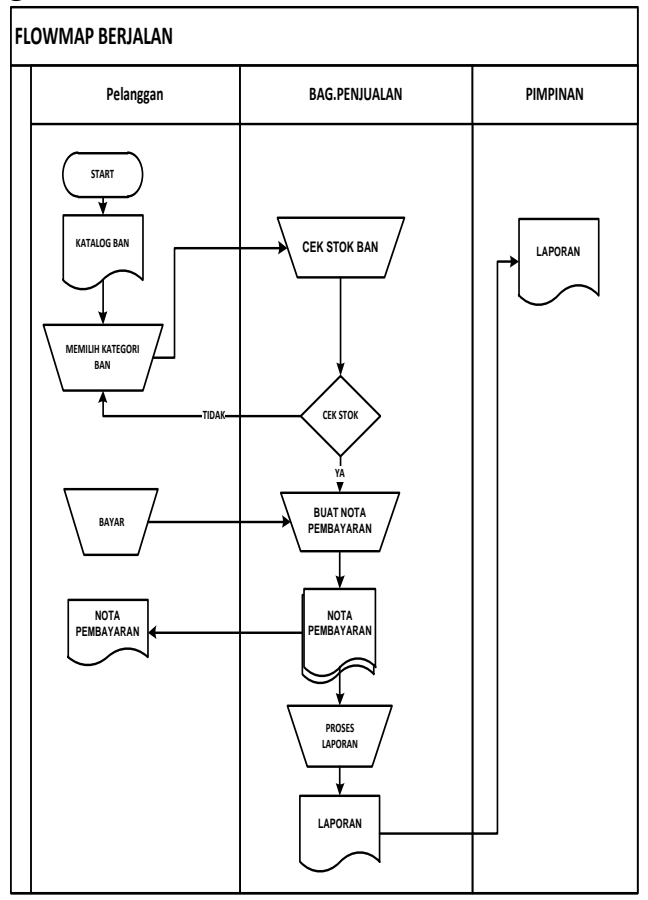

Gambar 1. Flowmap Sistem Stok Barang Yang sedang berjalan

\subsection{Analisis Sistem Usulan}

Sistem yang diusulkan bertujuan untuk memfasilitasi kekurangan yang terjadi pada sistem yang sedang berjalan saat ini, terutama pada bidang penjualan produk ban. Sistem yang 
JURNAL NUANSA INFORMATIKA

Volume 12 Nomor 1, Januari 2018

diusulkan untuk penjualan Ban di Toko Lingga Ban digambarkan melalui flowmap berikut ini.

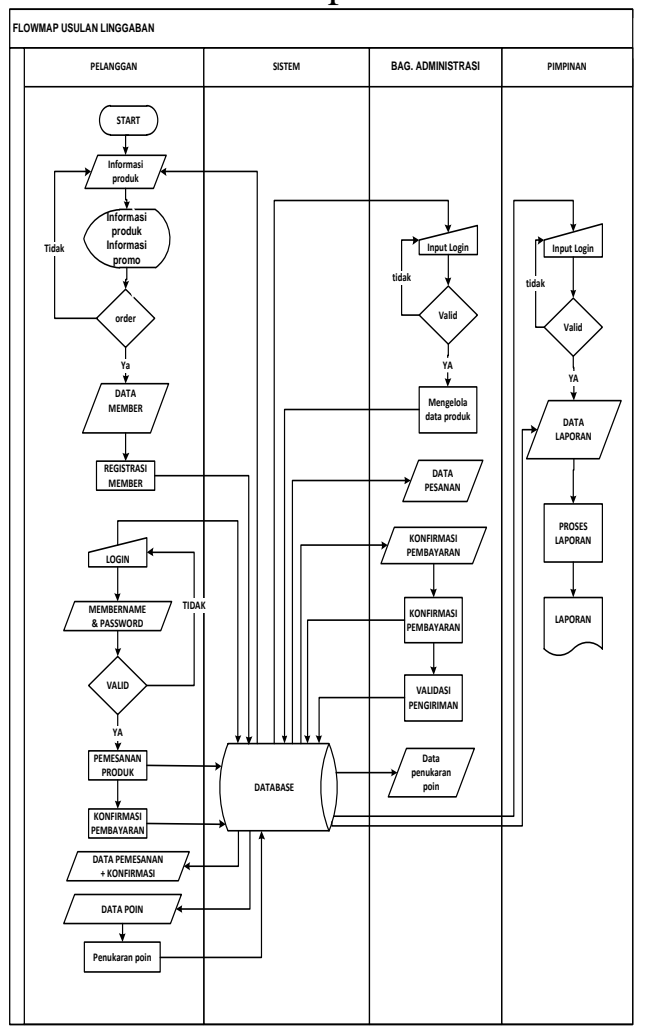

Gambar 2. Flowmap Sistem Yang Diusulkan.

\subsection{Diagrak Kontek}

Diagram konteks dibuat untuk menggambarkan sumber serta tujuan data yang akan diproses atau dengan kata lain diagram tersebut digunakan untuk menggambarkan sistem secara umum atau global dari keseluruhan sistem yang ada.

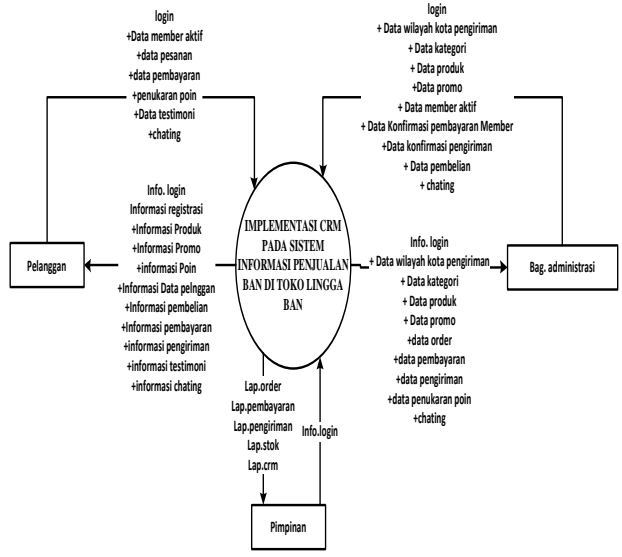

Gambar 3. Diagram Konteks
p-ISSN : 1858-3911, e-ISSN : 2614-5405

https://journal.uniku.ac.id/index.php/ilkom

\subsection{Data Flow Diagram (DFD)}

Data flow diagram ini adalah suatu Networks yang menggambarkan suatu sistem komputerisasi, manual atau golongan dari keduanya, yang penggambarannya disusun dalam bentuk kumpulan komponen sistem yang saling berhubungan sesuai dengan aturan mainnya. Dibawah ini DFD Level 0 tentang sistem yang akan dibuat:

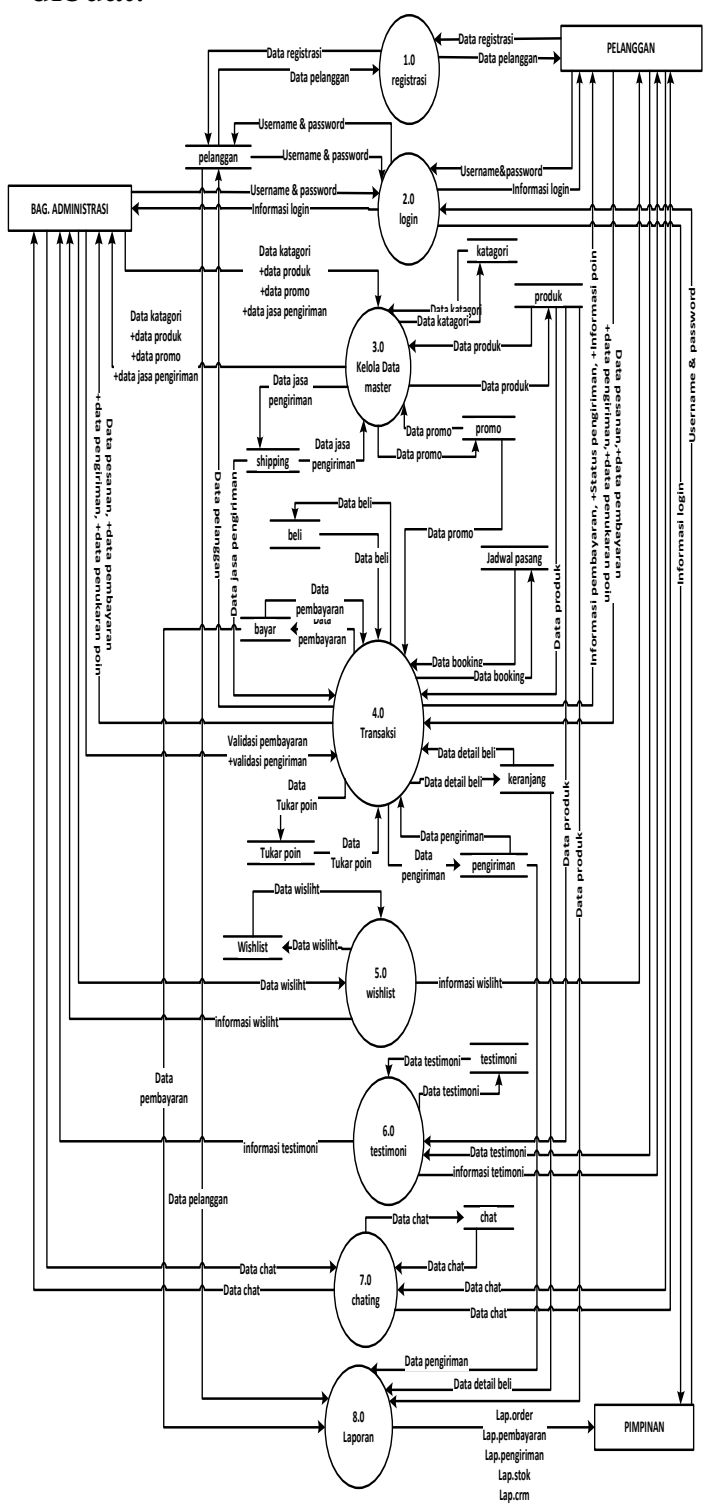

Gambar 4. Data Flow Diagram (DFD)

Level 0

Berdasarkan data flow diagram diatas maka berikut 
penjelasan alur data yang dibangun tersebut :

1. Proses 1.0 Registrasi Pelanggan.

Prose registrasi merupakan proses yang dilakukan oleh pelanggan untuk memasukkan data dan identitas pribadi dari pelanggan.

2. Proses 2.0 Login.

Proses login dilakukan oleh pelanggan, bagian administrasi, dan pimpinan dengan memasukan username dan password.

3. Proses 3.0 kelola Data Master.

Poses kelola data master merupakan proses yang dilakukan oleh bagian administrasi untuk mengelola kategori barang, data produk, data jasa pengiriman dan data promo.

4. Proses 4.0 Transaksi.

Proses transaksi dilakukan oleh pelanggan dengan mengisi data pesanan, data pembayaran dan data booking produk bila pelanggan ingin membooking produk atau data dikirim bila belanggan tidak membooking yang selanjutnya akan di validasi oleh bagian administrasi.

5. Proses 5.0 Wishlist

Proses wishlist dilakukan oleh pelanggan sebagai daftar harapan atau keinginan pada saat pelanggan berbelanja tapi pelanggan tersebut belum ingin membayarnya atau karena stok yang diinginkan kosong.

6. Proses 6.0 Testimoni

Proses testimoni digunakan pelanggan untuk menyampaikan komentar pada salah satu produk melalui website.

7. Proses 7.0 Chating

Proses chating berfungsi untuk melakukan obrolan dalam bentuk tulisan dengan pihak Toko.

8. Proses 8.0 Laporan
p-ISSN : 1858-3911, e-ISSN : 2614-5405

https://journal.uniku.ac.id/index.php/ilkom

Proses ini menampilkan laporan berupa laporan order, laporan pembayaran, laporan pengiriman, laporan stok dan laporan crm.

\subsection{Entity Relatinship Diagram}

Pada model Entity-Relationship semesta data yang ada di dunia nyata diterjemahkan menjadi sekumpulan objek dasar yang disebut entitas (entity) dan relasi antara objek-objek tersebut (relationship). Kedua komponen dasar ini dideskripsikan lebih jauh melalui sejumlah atribut. Entity Relationship diagram (Diagram E-R) adalah gambaran keseluruhan struktur logis dari basis data.

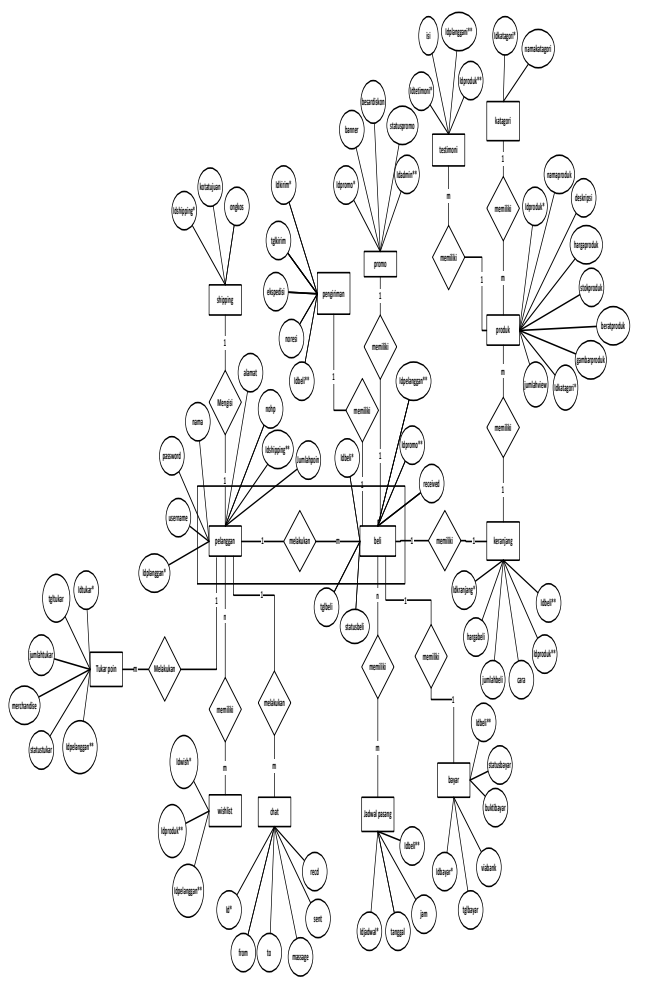

Gambar 5. Entity Relationship Diagram (ERD)

\subsection{Implementasi Antar Muka}

3.6.1 Tampilan Login 
JURNAL NUANSA INFORMATIKA

Volume 12 Nomor 1, Januari 2018

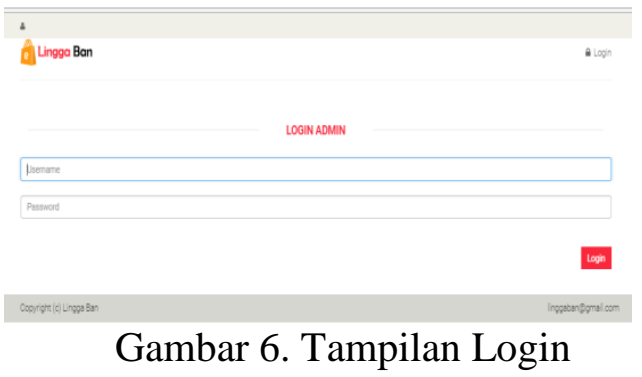

Aplikasi Gambar 6. merupakan tampilan awal pada saat akan memasuki aplikasi sistem pengelolaan pada Toko Lingga Ban.

\subsubsection{Tampilan Menu Master admin}
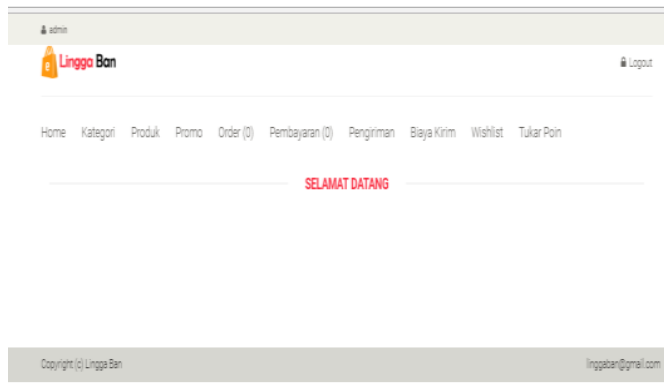

Gambar 7. Form Menu Master Administrator

3.6.3 Menu Form Menu Master Kategori
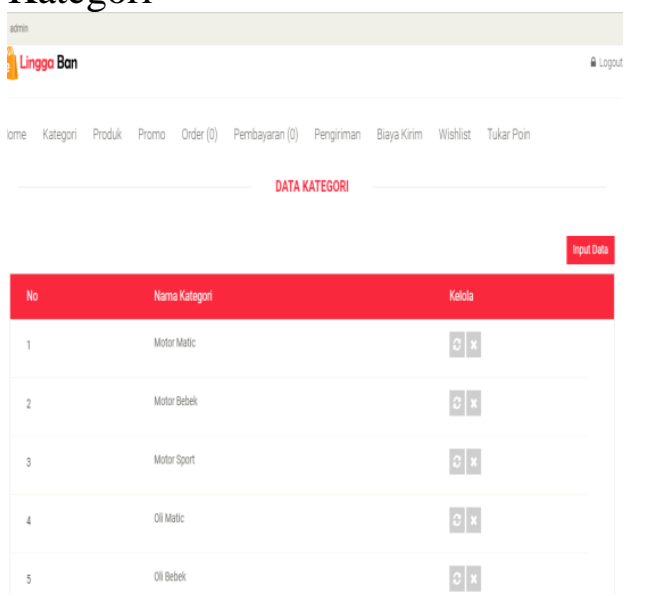

p-ISSN : 1858-3911, e-ISSN : 2614-5405

https://journal.uniku.ac.id/index.php/ilkom

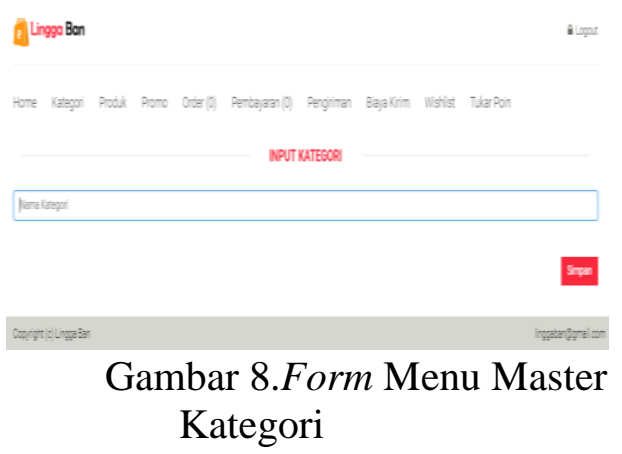

\subsubsection{Form Order Masuk}

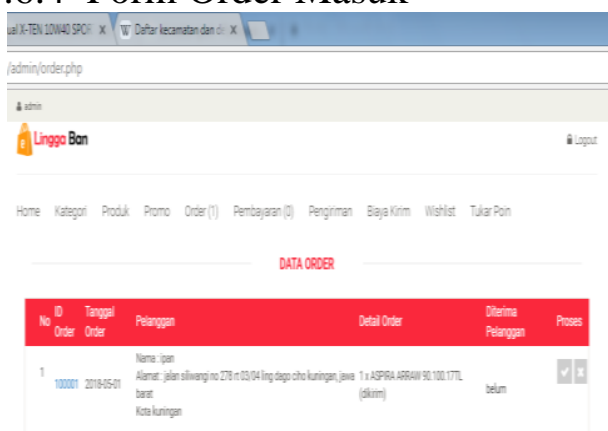

Gambar 9. Form Order masuk

\subsubsection{Form Status Pengiriman}

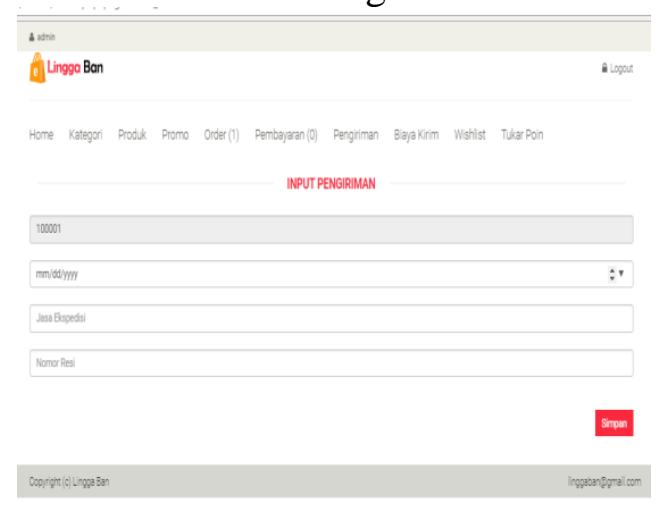

Gambar 10. Form Konfirmasi Status Kiriman

3.6.6 Form Menu Laporan Stok Barang 


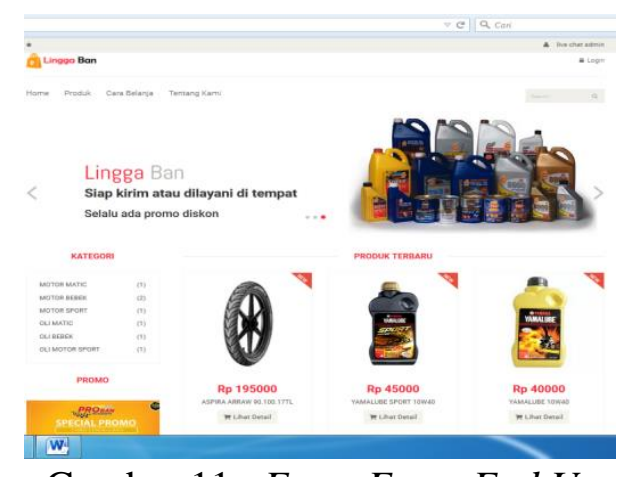

Gambar 11. Form Front End User

\section{KESIMPULAN}

1. Meningkatkan proses bisnis penjualan di Toko Lingga Ban secara lebih luas juga terstruktur dan rinci.

2. Penerapan sistem komputerisasi untuk menggantikan proses manual sangat menunjang terhadap terpenuhinya kebutuhan informasi yang relatif cepat, tepat dan akurat.

3. Proses pengolahan data dengan menggunakan media komputer sangat praktis bila dibandingkan dengan cara manual dimana, proses jual beli yang terjadi di Toko Lingga Ban Kuningan akan dibuat dan ditunjang dengan model bisnis terbarukan yang lebih optimal berdasarkan kebutuhan dan kemudahan bagi pelanggan juga didesain dengan integrasi yang baik sehingga menghasilkan proses bisnis yang tepat.

\section{SARAN}

1. Toko Lingga Ban Kuningan dapat segera mengoptimalkan perangkat keras dan perangkat lunak yang ada untuk membangun sebuah sistem yang dapat menunjang proses peningkatan jual beli secara terkomputerisasi sehingga akan lebih memudahkan para pelanggan dalam mengolah data dan menerima informasi,

2. Untuk bagian yang terkait dengan sistem, agar dapat meningkatkan
p-ISSN : 1858-3911, e-ISSN : 2614-5405

https://journal.uniku.ac.id/index.php/ilkom

sumber daya manusia di Toko Lingga Ban Kuningan agar menjadi lebih handal untuk meningkatkan kualitas kerja.

3. Perlu dibuatnya sebuah sistem jual beli yang berbasis web atau online yang lebih baik dan modern sehingga pada masa yang akan datang proses bisnis Toko Lingga Ban Kuningan dapat dilakukan dengan lebih profesional.

\section{DAFTAR PUSTAKA}

Bin Ladjamudin, Al Bahra. 2013, Analisis dan Desain Sistem Informasi, Graha Ilmu, Yogyakarta.

Sutarman,2009. Pengantar tekhnologi Informasi. Jakarta. Bumi Aksara

Jogiyanto, HM. 2009, "Sistem Teknologi Informasi”, Penerbit Andi, Yogyakarta.

Kristanto, Andri. 2008. Perancangan Sistem Informasi Dan Aplikasi. Gava Media. Yogyakarta

Mulyanto, Agus 2009. Sistem Informasi Konsep dan Aplikasi. Pustaka Pelajar. Yogyakarta.

Jogiyanto, HM. 2005, "Analisis dan Desain Sistem Informasi :Pendekatan Terstruktur Teori dan Praktik Aplikasi Bisnis", Penerbit Andi, Yogyakarta.

Susanto, Azhar 2013. Sistem Informasi Akutansi. Lingga Jaya Bandung.

Sutarman,2009. Pengantar tekhnologi Informasi. Jakarta. Bumi Aksara

Laudon, 2010. Management Information Syistem: Managing The Digital Firm. Prentic Hall. New Jersey

Marakas George M, 2008. Management Information Syistem $8^{\text {th }}$ Education. McGraw Hill. New York.

Philip Kolter, 2009. Marketing Management, 11th edition, New Jersey .Prentice Hall.

Buttle Francis, 2007. Customer Relation Management (Manajemen Hubungan 
Pelanggan) Concept And Tool. Banyumedia. Malang

Kalakota.R.dan Robinshon,M. .2001. EBusiness 2.0 Roadmap for success. Massachusettts. Addsion Wesley Longman inc.

Turban, Efraim, et al. 2004. Electronic Commerce a Managerial Perspective. New Jersey, Pearson Education International.

Fathansyah. 2012.Basis Data Edisi Revisi. Bandung: Informatika

S, Rosa, Shalahuddin, M. (2013). Rekayasa Perangkat Lunak. Penerbit Informatika Bandung, Bandung.

Blanco, J.A. and Upton, D., 2009, Codeigniter 1.7, Packt Publishing, Birmingham.

Priyanto Hidayatullah \& Jauhari Khairul Kawistara 2014. Pemrograman Web , Bandung : Penerbit : Informatika Bandung

Peranginangin, Kasiman. 2006. Aplikasi WEB dengan PHP dan MySQL, Yogyakarta: Andi

Kadir, Abdul. 2009. Membuat Aplikasi Web dengan PHP dan Database $M y S Q L, \quad$ Penerbit ANDI, Yogyakarta.

Agung, Leo. 2011. "Character Education Integration in Social Studies Learning".International Journal of History Education, 12 (2): 392-403.

Hakim, Lukmanul, 2008, Membongkar Trik Rahasia Para Master PHP, LOKOMEDIA, Yogyakarta. 